\title{
Gender difference in determinant factors of being overweight among the 40-70-year- old population of Kharameh cohort study, Iran
}

Seyed Alireza Dastgheib ${ }^{1}$, Abbas Rezaianzadeh², Najmeh Maharlouei ${ }^{3^{*}}$, Salar Rahimikazerooni ${ }^{2}$ and Kamran B. Lankarani ${ }^{3}$

\begin{abstract}
Background: Iranians face being overweight as one of the most common health problems, which is more prevalent among women. This study aimed to identify gender differences in determinants of being overweight in 40- to 70-year-old participants from Kharameh, Iran.

Methods: This cross-sectional study was conducted during 2015-2016. The total 10,663 inhabitants of Kharameh, Iran, aged 40-70 years old, were target population. Those with a body mass index (BMI) $<18.5$ or $>29.9$ were excluded. A checklist composed of socio-demographic, lifestyle, and BMI items was used; a $p$-value $<0.05$ was considered significant.
\end{abstract}

Results: Overall, $53.4 \%$ of 8222 participants were overweight. The prevalence of overweight women (62.7\%) was significantly higher $(p<0.001)$ than men $(43.6 \%)$.

The logistic regression model for men showed that being overweight was more likely among men with cigarette smoking history $(\mathrm{OR}=1.49)$ and those with a moderate physical activity level $(\mathrm{OR}=1.35)$, but less likely among those with a higher socio-economic status $(S E S)(O R=0.74)$. Among women, being overweight was associated with high SES $(O R=1.61)$, an education level below high school diploma $(O R=1.57)$ and primary school education $(O R=1.50)$, being married $(O R=2.39)$, widowed $(O R=2.11)$ and having a greater calorie intake $(O R=1.01)$. Being overweight was less likely among employed women $(O R=0.85)$, those with cigarette smoking history $(O R=0.65)$, and those with high $(\mathrm{OR}=0.72)$ and intensive physical activity $(\mathrm{OR}=0.73)$.

Conclusions: This study revealed the gender differences in determining factors affecting being overweight. As being overweight was more prevalent among women, the priority of health policies to control this issue should also be focused on women.

Keywords: Overweight, Gender difference, Socio-demographic factors, Iran

\footnotetext{
* Correspondence: najmeh.maharlouei@gmail.com

${ }^{3}$ Health Policy Research Center, Institute of Health, Shiraz University of

Medical Sciences, Shiraz, Iran

Full list of author information is available at the end of the article
}

C C The Author(s). 2021 Open Access This article is licensed under a Creative Commons Attribution 4.0 International License, which permits use, sharing, adaptation, distribution and reproduction in any medium or format, as long as you give appropriate credit to the original author(s) and the source, provide a link to the Creative Commons licence, and indicate if changes were made. The images or other third party material in this article are included in the article's Creative Commons licence, unless indicated otherwise in a credit line to the material. If material is not included in the article's Creative Commons licence and your intended use is not permitted by statutory regulation or exceeds the permitted use, you will need to obtain permission directly from the copyright holder. To view a copy of this licence, visit http://creativecommons.org/licenses/by/4.0/ The Creative Commons Public Domain Dedication waiver (http://creativecommons.org/publicdomain/zero/1.0/) applies to the data made available in this article, unless otherwise stated in a credit line to the data. 


\section{Background}

High body mass index (BMI) is one of the most common health problems in both developed and developing countries [1]. It is one of the main reasons for morbidity, mortality, and even impaired quality of life [2]. Worldwide, being overweight is increasing [3]. According to the World Health Organization (WHO), more than 1.9 billion adults were overweight in 2016 [4].

Iran, like other countries, is facing the challenge of increasing number of overweight individuals. Based on a systematic review with data from January 2005 to January 2014, the range of overweight individuals among the Iranian adult population at the sub-national level was between 12.8 and $76.4 \%$ [5]. However, studies after 2014 in Iran have shown rates of being overweight to be 39.6\% in East Azerbaijan [6], 36.5\% in West Azerbaijan [7], between 34.1 and $63.6 \%$ among those aged above 20 years in Tehran [1, 8], and 43.4\% among 40-64-year-old people in Shahroud [9].

The existing literature shows associations between BMI and some socio-demographic characteristics such as age, gender, marital status, race, educational level, occupational status, and socio-economic status (SES) $[1,6$, 10-12]. However, there has been some controversial results regarding some of the associations, such as SES and BMI [9, 13, 14]. In addition, studies have identified low level of physical activity as a significant risk factor for being overweight $[15,16]$. Smoking status has also been found to be inversely associated with BMI [11].

However, there are differences in determining factors among genders [17]. The prevalence of overweight individuals is higher among women $[1,6,9,12]$. Studies have shown that married, unemployed, and low-educated women were at a higher risk of being overweight $[1,11$, 12, 17]. Moreover, smoking status was associated with higher weight only in women [17]. On the other hand, another study presented different findings, showing that among both genders, nonsmokers were more expected to be overweight or obese [6].

The current study aimed to identify the association between socio-demographic and lifestyle factors and being overweight in the 40-70-year-old population of Kharameh city. As the prevalence of being overweight was higher among women $[6,9,12]$, determinants associated with being overweight that differed among men and women were also investigated.

\section{Methods}

\section{Study design and participants}

This analytical cross-sectional study was conducted using the baseline data of the Kharameh cohort study, a branch of the Prospective Epidemiological Research Studies in Iran (PERSIAN cohort). The rationale, objectives, and design of the PERSIAN cohort study have earlier been published $[18,19]$. This study was approved by Shiraz University of Medical Sciences Ethics Committee (IR.sums.med.rec.1398.340).

Kharameh is one of the counties of Fars province, the fifth populous province located in southwestern Iran. According to the latest national census in 2016, its population was $54,864,14,447$ of whom were 40 to 70 years old [20]. Out of 22,939 participants in the Fars cohort [18], 8222 individuals were aged 40 to 70 years old, and all of them were entered into the study. The inclusion criteria were living in Kharameh for at least 1 year before the start of this study, and willingness to participate. Participants with a BMI below 18.5 or greater than 29.99 were excluded.

\section{Data gathering tools}

Data was collected with a checklist consisting of three main parts: socio-demographic characteristics, lifestyle variables, and anthropometric indices. Socio-demographic variables were comprised of age, gender, marital status (married, single, widowed/divorced), educational level (illiterate, under diploma, high school diploma, university degree), occupational status (employed, unemployed), and SES (low, lower-middle, upper-middle, and high). The SES of households was calculated using the principal component analysis method and included assets of the participants such as type of residence (owned or rented), residential area (in square meters), number of rooms, ownership of landline telephone, washing machine, dishwasher, flat-screen $\mathrm{TV}$, refrigerator, vacuum cleaner, or personal computer/laptop, access to Internet at home, access to a shower and toilet, and car ownership status and its value.

Lifestyle variables included history of cigarette smoking (yes-no), history of hookah smoking (yes-no), history of alcohol drinking (yes-no), level of physical activity (light, moderate, high, and intensive), and calorie intake. Participants' daily physical activity was measured through metabolic equivalent rates (METs) using a selfreported validated questionnaire. One MET is equal to resting metabolic rate, the amount of oxygen consumed at rest which is about $3.5 \mathrm{ml} 02 / \mathrm{kg} / \mathrm{min}$. As four METs

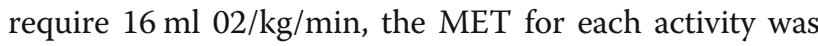
extracted using a compendium of physical activities [18]. To measure calorie intake, the food frequency questionnaire (FFQ) was used. It contains 130 food items [19], and has been validated for Iranian populations based on their culture and food habits [21]. Participant BMIs were calculated as weight in kilograms divided by square of height in meters. According to WHO, BMI is considered normal if it is between 18.5 and 25 and overweight if it is between 25.0 and 30 [22]. The dependent variable used in this study was the classification variable ( 0 for those with normal weight, 1 for overweight participants). 


\section{Data analysis}

The Statistical Package for Social Sciences (SPSS) software version 21 (IBM, Armonk, NY, USA) was used for data analysis. Descriptive analysis including mean, standard deviation, and frequency distribution was done to assess demographic and anthropometric characteristics. Chisquare test was used as a univariate analysis for associations between the independent variables and the outcome variable. A binary logistic regression analysis was applied to determine the predictive variables of being overweight among 40- to 70-year-old adults in Kharameh. According to the univariate analyses, variables with $p \leq 0.2$ had the necessary requirement to be entered into the regression model. The final model was reported with odds ratios (ORs) and 95\% confidence intervals (CIs). A $p$-value less than 0.05 was considered significant.

\section{Results}

Overall, 8222 adults were studied, out of which 51.4\% were women. The mean BMI for the total population was $24.99 \pm 2.9 \mathrm{~kg} / \mathrm{m}^{2}, \quad 24.34 \pm 2.9 \mathrm{~kg} / \mathrm{m}^{2}$ for men and $25.62 \pm 2.8 \mathrm{~kg} / \mathrm{m}^{2}$ for women. The prevalence of being overweight was $53.4 \%$ and higher among women $(62.7 \%)$ than men (43.6\%). Other anthropometric information is shown in Table 1.

Regardless of gender, the variables of age, SES, employment status, marital status, level of education, physical activity, and history of alcohol drinking and cigarette smoking, differed significantly $(p<0.001)$ between overweight individuals and those with normal weight (Table 2).

BMI was also statistically different between men and women $(p<0.001)$. Among the studied variables, SES $(p<0.001)$, education level $(p<0.001)$, physical activity $(p<0.001)$, history of cigarette smoking $(p<0.001)$, and history of hookah smoking $(p=0.008)$ were significantly different between overweight men and those with a normal weight (Table 2).

For women, SES $(p<0.001)$, employment status $(p=$ $0.001)$, marital status $(p<0.001)$, education level $(p<0.001)$, physical activity $(p=0.016)$, history of cigarette smoking $(p=0.001)$, and calorie intake $(p=0.003)$ were significantly different between overweight women and those with a normal weight (Table 2).

Results from logistic regression to predict factors associated with being overweight in the total population showed that women $(\mathrm{OR}=2.002)$, those with uppermiddle and high SES $(\mathrm{OR}=1.277$ and 1.684, respectively), married $(\mathrm{OR}=1.975)$ and widowed/divorced people $(\mathrm{OR}=1.699)$, and among individuals with any level of education up to primary school education $(p<0.05)$ were more likely to be overweight. However, people with a history of cigarette smoking $(\mathrm{OR}=0.630$, $p<0.001)$, with high $(\mathrm{OR}=0.802)$ and intensive physical activity levels $(\mathrm{OR}=0.720, p<0.001)$ were less likely to be overweight (Table 3).

The logistic regression model for men aged 40 to 70 years old showed that being overweight was less likely in those with higher SES than in those with a low SES. Other factors involved in overweight men were history of cigarette smoking $(\mathrm{OR}=1.495 ; p=0.02)$ and moderate physical activity $(\mathrm{OR}=1.355 ; p=0.007)$ (Table 4$)$.

The result of the logistic regression analysis showed that being overweight was more likely among women with high SES (OR $=1.616 ; p<0.001)$, women with an educational level below diploma or primary school $(p<0.001)$, and married (OR $=2.396 ; p<0.001)$ or widowed women $(\mathrm{OR}=2.109 ; p<0.001)$. Moreover, women with a higher calorie intake were more likely to be overweight $(\mathrm{OR}=1.000 ; p=0.018)$. It was also revealed that being overweight is less likely in employed women than unemployed $(\mathrm{OR}=0.846 ; p=0.030)$, also less likely in women with a history of cigarette smoking $(\mathrm{OR}=0.648 ; p=0.012)$, and women with a high (OR: $0.718 ; p=0.001)$ or intensive $(\mathrm{OR}=0.730 ; p=0.008)$ level of physical activity (Table 5).

\section{Discussion}

This study investigated gender differences in determinants of being overweight among the 40- to 70-year-old population in Kharameh, located in southwestern Iran. About half of the study population was overweight. Being overweight was more prevalent among women than

Table 1 Anthropometric indices in the studied sample according to gender

\begin{tabular}{llll}
\hline Anthropometric Variable & Total & Gender & Women \\
\cline { 3 - 4 } & & Men & $3992(48.6)$ \\
Number of subjects & $8222(100.0)$ & $170.79( \pm 7.1)$ & $156.91( \pm 6.3)$ \\
Height $(\mathrm{cm})$ & $163.65( \pm 9.6)$ & $71.14( \pm 10.3)$ & $63.20( \pm 8.5)$ \\
Weight $(\mathrm{kg})$ & $67.05( \pm 10.2)$ & $24.34( \pm 2.9)$ & $25.62( \pm 2.8)$ \\
BMl $\left(\mathrm{kg} / \mathrm{m}^{2}\right)$ & $24.99( \pm 2.92)$ & $2249(56.4)$ & $1579(37.3)$ \\
Normal weight $(18.5 \leq \mathrm{BMl}<25.0)$ & $3828(46.6)$ & $1741(43.6)$ & $2649(62.7)$ \\
Overweight $(25.0 \leq \mathrm{BMl}<30.0)$ & $4390(53.4)$ & &
\end{tabular}

Data is reported as mean ( \pm SD) or frequency (\%) as indicated 
Table 2 Association between individual characteristics and normal weight and overweight among studied population

\begin{tabular}{|c|c|c|c|c|c|}
\hline Variable & Gender & Sub-group & Number of subjects (\%) & Normal weight (\%) & Overweight (\%) \\
\hline \multirow[t]{12}{*}{ Age group } & Men & $40-49$ & $1988(49.8)$ & $1148(51.1)$ & $840(48.3)$ \\
\hline & & $50-59$ & $1441(36.1)$ & $791(35.2)$ & $648(37.3)$ \\
\hline & & $\geq 60$ & $559(14.0)$ & 309 (13.7) & $250(14.4)$ \\
\hline & & ${ }^{1} p$-value & & 0.229 & \\
\hline & Women & $40-49$ & $1659(39.2)$ & $632(40.1)$ & $1026(38.7)$ \\
\hline & & $50-59$ & $1504(35.6)$ & $563(35.7)$ & $940(35.5)$ \\
\hline & & $\geq 60$ & $1066(25.2)$ & $383(24.3)$ & $683(25.8)$ \\
\hline & & ${ }^{1} p$-value & & 0.51 & \\
\hline & Total & $40-49$ & $3647(44.4)$ & $1780(46.5)$ & $1866(42.5)$ \\
\hline & & $50-59$ & $2945(35.8)$ & $1354(35.4)$ & $1588(36.2)$ \\
\hline & & $\geq 60$ & $1625(19.8)$ & $692(18.1)$ & $933(21.3)$ \\
\hline & & ${ }^{1} p$-value & & $<0.001$ & \\
\hline \multirow[t]{15}{*}{ SES } & Men & Low & $801(20.1)$ & $522(23.2)$ & $279(16.0)$ \\
\hline & & Lower-middle & $874(21.9)$ & $535(23.8)$ & $338(19.4)$ \\
\hline & & Upper-middle & $840(21.0)$ & $474(21.1)$ & $366(21.0)$ \\
\hline & & High & $1477(37.0)$ & $718(31.9)$ & $758(43.5)$ \\
\hline & & ${ }^{1} p$-value & & $<0.001$ & \\
\hline & Women & Low & $1261(29.8)$ & $535(33.9)$ & $725(27.4)$ \\
\hline & & Lower-middle & $1383(32.7)$ & $531(33.6)$ & $852(32.2)$ \\
\hline & & Upper-middle & $1078(25.5)$ & $373(23.6)$ & $704(26.6)$ \\
\hline & & High & $508(12.0)$ & $140(8.9)$ & $368(13.9)$ \\
\hline & & ${ }^{1} p$-value & & $<0.001$ & \\
\hline & Total & Low & $2062(25.1)$ & $1057(27.6)$ & $1004(22.9)$ \\
\hline & & Lower-middle & $2257(27.5)$ & $1066(27.8)$ & $1190(27.1)$ \\
\hline & & Upper-middle & $1918(23.3)$ & $847(22.1)$ & $1070(24.4)$ \\
\hline & & High & $1985(24.1)$ & $858(22.4)$ & $1126(25.6)$ \\
\hline & & ${ }^{1} p$-value & & $<0.001$ & \\
\hline \multirow[t]{9}{*}{ Employment status } & Men & Employed & $3402(85.2)$ & 1925 (85.6) & $1477(84.8)$ \\
\hline & & Unemployed & $590(14.8)$ & $324(14.4)$ & $264(15.2)$ \\
\hline & & ${ }^{1} P$-value & & 0.266 & \\
\hline & Women & Employed & $1141(27.0)$ & $472(29.9)$ & $1980(74.7)$ \\
\hline & & Unemployed & $3089(73.0)$ & $1107(70.1)$ & $669(25.3)$ \\
\hline & & ${ }^{1} p$-value & & 0.001 & \\
\hline & Total & Employed & $4543(55.3)$ & $2397(62.6)$ & $2146(48.9)$ \\
\hline & & Unemployed & $3679(44.7)$ & $1431(37.4)$ & $2244(51.1)$ \\
\hline & & ${ }^{1} p$-value & & $<0.001$ & \\
\hline \multirow[t]{8}{*}{ Marital status } & Men & Single & $21(0.5)$ & $11(0.5)$ & $9(0.5)$ \\
\hline & & Married & $3940(98.7)$ & $2217(98.6)$ & $1722(98.9)$ \\
\hline & & Widowed/divorced & $31(0.8)$ & $21(0.9)$ & $10(0.6)$ \\
\hline & & ${ }^{1} p$-value & & 0.437 & \\
\hline & Women & Single & $116(2.7)$ & $63(4.0)$ & $53(2.0)$ \\
\hline & & Married & $3445(81.4)$ & $1241(78.6)$ & $2202(83.1)$ \\
\hline & & Widowed/divorced & $669(15.8)$ & $275(17.4)$ & $394(14.9)$ \\
\hline & & ${ }^{1} p$-value & & $<0.001$ & \\
\hline
\end{tabular}


Table 2 Association between individual characteristics and normal weight and overweight among studied population (Continued)

\begin{tabular}{|c|c|c|c|c|c|}
\hline Variable & Gender & Sub-group & Number of subjects (\%) & Normal weight (\%) & Overweight (\%) \\
\hline & Total & Single & $137(1.7)$ & $74(1.9)$ & $62(1.4)$ \\
\hline & & Married & $7385(89.8)$ & $3458(90.3)$ & $3924(89.4)$ \\
\hline & & Widowed/divorced & $700(8.5)$ & $296(7.7)$ & $404(9.2)$ \\
\hline & & ${ }^{1} p$-value & & 0.013 & \\
\hline \multirow[t]{15}{*}{ Education level } & Men & Illiterate & $843(21.1)$ & $515(22.9)$ & $328(18.8)$ \\
\hline & & Under diploma & $1610(40.3)$ & $915(40.7)$ & $694(39.9)$ \\
\hline & & high school diploma & $1178(29.5)$ & $651(28.9)$ & $526(30.2)$ \\
\hline & & University degree & $361(9.0)$ & $168(7.5)$ & $193(11.1)$ \\
\hline & & ${ }^{1} P$-value & & $<0.001$ & \\
\hline & Women & Illiterate & $1747(41.3)$ & $767(48.6)$ & $979(37.0)$ \\
\hline & & Under diploma & $1865(44.1)$ & $619(39.2)$ & $1246(47.0)$ \\
\hline & & high school diploma & $494(11.7)$ & $153(9.7)$ & $340(12.8)$ \\
\hline & & University degree & $124(2.9)$ & $40(2.5)$ & $84(3.2)$ \\
\hline & & ${ }^{1} p$-value & & $<0.001$ & \\
\hline & Total & Illiterate & $2590(31.5)$ & $1282(33.5)$ & $1307(29.8)$ \\
\hline & & Under diploma & $3475(42.3)$ & $1534(40.1)$ & $1940(44.2)$ \\
\hline & & high school diploma & $1672(20.3)$ & $804(21.0)$ & $866(19.7)$ \\
\hline & & University degree & $485(5.9)$ & $208(5.4)$ & $277(6.3)$ \\
\hline & & ${ }^{1} p$-value & & $<0.001$ & \\
\hline \multirow[t]{15}{*}{ Physical activity } & Men & Light & $1178(29.5)$ & $617(27.4)$ & $559(32.1)$ \\
\hline & & Moderate & $650(16.3)$ & $322(14.3)$ & $328(18.8)$ \\
\hline & & High & $577(14.5)$ & $314(14.0)$ & $263(15.1)$ \\
\hline & & Intensive & 1587 (39.8) & $996(44.3)$ & $591(33.9)$ \\
\hline & & ${ }^{1} p$-value & & $<0.001$ & \\
\hline & Women & Light & $836(19.8)$ & $286(18.1)$ & $549(20.7)$ \\
\hline & & Moderate & 1349 (31.9) & $480(30.4)$ & $868(32.8)$ \\
\hline & & High & $1444(34.1)$ & $571(36.2)$ & $873(33.0)$ \\
\hline & & Intensive & $601(14.2)$ & $242(15.3)$ & $359(13.6)$ \\
\hline & & ${ }^{1} p$-value & & 0.016 & \\
\hline & Total & Light & $2014(24.5))$ & $903(23.6)$ & $1108(25.2)$ \\
\hline & & Moderate & $1999(24.3)$ & $802(21.0)$ & $1196(27.2)$ \\
\hline & & High & $2021(24.6)$ & $885(23.1)$ & $1136(25.9)$ \\
\hline & & Intensive & $2188(26.6)$ & $1238(32.3)$ & $950(21.6)$ \\
\hline & & ${ }^{1} p$-value & & $<0.001$ & \\
\hline \multirow[t]{9}{*}{ History of alcohol drinking } & Men & Yes & $458(11.5)$ & $266(11.8)$ & $191(11.0)$ \\
\hline & & No & $3534(88.5)$ & $1983(88.2)$ & $1550(89.0)$ \\
\hline & & ${ }^{1} p$-value & & 0.214 & \\
\hline & Women & Yes & $6(0.1)$ & $3(0.2)$ & $3(0.1)$ \\
\hline & & No & $4224(99.9)$ & 1576 (99.8) & $2646(99.9)$ \\
\hline & & ${ }^{1} p$-value & & 0.401 & \\
\hline & Total & Yes & 464 (5.6) & $269(7.0)$ & $194(4.4)$ \\
\hline & & No & 7758 (94.4) & 3559 (93.0) & 4196 (95.6) \\
\hline & & ${ }^{1} P$-value & & $<0.001$ & \\
\hline History of cigarette smoking & Men & Yes & 2067 (51.8) & $1277(56.8)$ & $789(45.3)$ \\
\hline
\end{tabular}


Table 2 Association between individual characteristics and normal weight and overweight among studied population (Continued)

\begin{tabular}{|c|c|c|c|c|c|}
\hline Variable & Gender & Sub-group & Number of subjects (\%) & Normal weight (\%) & Overweight (\%) \\
\hline & & No & $1925(48.2)$ & $972(43.2)$ & $952(54.7)$ \\
\hline & & $p$-value & & $<0.001$ & \\
\hline & Women & Yes & $146(3.5)$ & $74(4.7)$ & $72(2.7)$ \\
\hline & & No & 4084 (96.5) & 1505 (95.3) & 2577 (97.3) \\
\hline & & ${ }^{1} p$-value & & 0.001 & \\
\hline & Total & Yes & $2213(26.9)$ & $1351(35.3)$ & 861 (19.6) \\
\hline & & No & $6009(73.1)$ & $2477(64.7)$ & $3529(80.4)$ \\
\hline & & ${ }^{1} p$-value & & $<0.001$ & \\
\hline \multirow[t]{9}{*}{ History of hookah smoking } & Men & Yes & $384(9.6)$ & $193(8.6)$ & $190(10.9)$ \\
\hline & & No & $3608(90.4)$ & $2056(91.4)$ & $1551(89.1)$ \\
\hline & & ${ }^{1} p$-value & & 0.008 & \\
\hline & Women & Yes & $58(1.4)$ & $22(1.4)$ & $35(1.3)$ \\
\hline & & No & $4172(98.6)$ & 1557 (98.6) & $2614(98.7)$ \\
\hline & & $p$-value & & 0.472 & \\
\hline & Total & Yes & $442(5.4)$ & $215(5.6)$ & $225(5.1)$ \\
\hline & & No & 7780 (94.6) & $3613(94.4)$ & 4165 (94.9) \\
\hline & & ${ }^{1} p$-value & & 0.324 & \\
\hline \multirow[t]{6}{*}{ Calorie intake* } & Men & - & $3431.00 \pm 1087.81$ & $3421.85 \pm 1072.11$ & $3424.06 \pm 1106.64$ \\
\hline & & ${ }^{2} p$-value & & 0.815 & \\
\hline & Women & & $3126.73 \pm 1002.43$ & $3053.18 \pm 980.16$ & $3148.93 \pm 1011.13$ \\
\hline & & ${ }^{2} p$-value & & 0.003 & \\
\hline & Total & & $3261.38 \pm 1051.94$ & $3269.76 \pm 1050.84$ & $3257.52 \pm 1058.32$ \\
\hline & & ${ }^{2} p$-value & & 0.599 & \\
\hline
\end{tabular}

All data is reported as frequency (\%), except calorie intake which is reported as Mean ( \pm Standard Deviation)

${ }^{1} \mathrm{Chi}$-square test was used

${ }^{2} \mathrm{~T}$ test was used

men $(62.7 \%$ versus $43.6 \%)$, which is in line with previous studies $[6,9,12,13]$.

Gender, SES, marital status, educational level, smoking, and level of physical activity were found to be determinant factors of being overweight in the population under study. Female gender was a predictor for being overweight in the studied population $[6,9,12,13]$; therefore, a gender-based analysis was also reported. In addition, being overweight was more likely among individuals with upper-middle and high SES. Khabazkhoob et al. (2017) confirmed that higher SES was significantly correlated with being overweight in the middle-aged population [9]. Probable reasons might be the prevalence of diseases such as hypothyroidism or diabetes mellitus in such age groups $[23,24]$ and the use of certain drugs and their metabolic side effects which may result in abnormal BMI [25]. Moreover, consistent with previous findings $[1,6]$ being overweight could be due to less attention paid to being in shape after marriage [26], as it was more likely to be overweight in married and widowed/divorced people. Individuals with any level of education were also at more risk of being overweight compared with those illiterate. As the educational level of the majority of the participants was illiterate or under diploma, the results about the relationship between educational level and being overweight should be interpreted with caution; the number of individuals with a university degree, whose nutritional literacy is expected to be significantly higher, was not enough for comparison. Clearly, the association between obesity and level of education is complex [27], and the following genderbased findings provide a clearer picture of the relationship. However, those with a history of cigarette smoking were less likely to be overweight, which might be a consequence of the role of smoking in suppressing appetite [28]. People with high and intensive physical activity were also less likely to be overweight. In line with the current findings, Bradbury et al. (2017) concluded that more intensive physical activity was associated with lower body fat percentage [29].

In women, the current study found SES, level of physical activity, employment status, educational level, marital status, and calorie intake to be determinant factors of being overweight. Women with a high SES were more 
Table 3 Regression model indicating factors associated with overweight in total population

\begin{tabular}{|c|c|c|c|}
\hline Variables retained in model & Odd's Ratio (OR) & 95\% Confidence Interval for OR & $p$-value \\
\hline \multicolumn{4}{|l|}{ Age } \\
\hline $40-49$ & 1 & & \\
\hline $50-59$ & 1.095 & $(0.989-1.213)$ & 0.080 \\
\hline$\geq 60$ & 1.123 & $(0.992-1.272)$ & 0.066 \\
\hline \multicolumn{4}{|l|}{ SES } \\
\hline Low & 1 & & \\
\hline Lower-middle & 1.119 & $(0.988-1.268)$ & 0.076 \\
\hline Upper-middle & 1.277 & $(1.119-1.458)$ & $<0.001$ \\
\hline High & 1.684 & $(1.458-1.945)$ & $<0.001$ \\
\hline \multicolumn{4}{|l|}{ Gender } \\
\hline Male & 1 & & \\
\hline Female & 2.002 & $(1.744-2.299)$ & $<0.001$ \\
\hline \multicolumn{4}{|l|}{ Education level } \\
\hline Illiterate & 1 & & \\
\hline Up to primary school & 1.365 & $(1.224-1.522)$ & $<0.001$ \\
\hline Under diploma & 1.343 & $(1.166-1.546)$ & $<0.001$ \\
\hline University degree & 1.317 & $(1.055-1.643)$ & 0.015 \\
\hline \multicolumn{4}{|l|}{ Marital status } \\
\hline Single & 1 & & \\
\hline Married & 1.975 & $(1.388-2.809)$ & $<0.001$ \\
\hline Widowed/divorced & 1.699 & $(1.162-2.485)$ & 0.006 \\
\hline \multicolumn{4}{|l|}{ History of cigarette smoking } \\
\hline No & 1 & & \\
\hline Yes & 0.630 & $(0.558-0.710)$ & $<0.001$ \\
\hline \multicolumn{4}{|l|}{ Employment status } \\
\hline Unemployed & 1 & & \\
\hline Employed & 0.940 & $(0.833-1.061)$ & 0.317 \\
\hline \multicolumn{4}{|l|}{ Physical activity } \\
\hline Light & 1 & & \\
\hline Moderate & 0.965 & $(0.844-1.103)$ & 0.598 \\
\hline High & 0.802 & $(0.699-0.919)$ & 0.002 \\
\hline Intensive & 0.720 & $(0.627-0.827)$ & $<0.001$ \\
\hline
\end{tabular}

likely to be overweight. Similar to these findings, Khabazkhoob et al. (2017) found that higher SES was significantly correlated with being overweight and obese [9]. Gouda et al. (2014) also confirmed that non-poor women were about 2 to 3 times more at risk of being overweight [30]. Moreover, women with high and intensive levels of physical activity were less likely to be overweight. Similarly, prior research identified low level of physical activity as a significant risk factor for being overweight $[15,16]$. Numerous scientific studies have explained it in the perspective of the nutritional transition in developing countries or the shift to Western diets with highly- saturated fats, sugar, and refined and processed foods in addition to an increased prevalence of physical inactivity $[30,31]$. The current study also revealed that being overweight was less prevalent among employed women. In line with these findings, Noh et al. showed that employed women had lower BMIs, although they also showed that employment status had various impacts on BMI by gender [32]. Sarma et al. found that unemployed women were at a 1.44-times higher risk of being overweight or obese than employed women [12]. In fact, unemployment can be associated with behavioral changes which affect diet with increased consumption of unhealthy 
Table 4 Regression model indicating factors associated with overweight in men

\begin{tabular}{llll}
\hline Variables retained in model & Odd's Ratio (OR) & $\mathbf{9 5 \%}$ Confidence Interval for OR & \\
\hline SES & 1 & & \\
Low & 0.587 & $0.463-0.744$ \\
Lower-middle & 0.659 & $0.522-0.832$ & $<001$ \\
Upper-middle & 0.742 & $0.585-0.941$ & $<001$ \\
High & 1 & & $<001$ \\
History of cigarette smoking & 1.495 & $(1.067-2.095)$ & \\
No & & & \\
Yes & 1 & $1.087-1.688$ \\
Physical activity & 1.355 & $0.980-1.461$ \\
Light & 1.196 & $0.829-1.228$ \\
Moderate & 1.009 & 0.007 \\
High & & 0.926 \\
Intensive & & \\
\hline
\end{tabular}

Table 5 Regression model indicating factors associated with overweight in women

\begin{tabular}{|c|c|c|c|}
\hline Variables retained in model & Odd's Ratio (OR) & 95\% Confidence Interval for OR & $p$-value \\
\hline \multicolumn{4}{|l|}{ SES } \\
\hline Low & 1 & & \\
\hline Lower-middle & 1.085 & $(0.926-1.272)$ & 0.313 \\
\hline Upper-middle & 1.187 & $(0.996-1.414)$ & 0.056 \\
\hline High & 1.616 & $(1.271-2.056)$ & $<0.001$ \\
\hline \multicolumn{4}{|l|}{ Education level } \\
\hline Illiterate & 1 & & \\
\hline Up to primary school & 1.505 & $(1.307-1.732)$ & $<0.001$ \\
\hline Under diploma & 1.567 & $(1.251-1.962)$ & $<0.001$ \\
\hline University degree & 1.570 & $(0.995-2.392)$ & 0.071 \\
\hline \multicolumn{4}{|l|}{ Employment status } \\
\hline Unemployed & 1 & & \\
\hline Employed & 0.846 & $(0.727-0.984)$ & 0.030 \\
\hline \multicolumn{4}{|l|}{ Marital status } \\
\hline Single & 1 & & \\
\hline Married & 2.396 & $(1.634-3.516)$ & $<0.001$ \\
\hline Widowed/divorced & 2.109 & $(1.400-3.177)$ & $<0.001$ \\
\hline \multicolumn{4}{|l|}{ History of cigarette smoking } \\
\hline No & 1 & & \\
\hline Yes & 0.648 & $(0.461-0.909)$ & 0.012 \\
\hline \multicolumn{4}{|l|}{ Physical activity } \\
\hline Light & 1 & & \\
\hline Moderate & 0.864 & $(0.717-1.042)$ & 0.125 \\
\hline High & 0.718 & $(0.595-0.865)$ & 0.001 \\
\hline Intensive & 0.730 & $(0.578-0.922)$ & 0.008 \\
\hline Calorie intake & 1.000 & $(1.000-1.000)$ & 0.018 \\
\hline
\end{tabular}


foods and less physical activity that can lead to weight gain [32, 33]. In addition, women with an educational level below high-school diploma were at a higher risk of being overweight. Previous studies have also confirmed that lower education is related with being overweight [12]. It could be secondary to a lower likelihood of women without a university degree to find a job, which can result in a more sedentary lifestyle. Being married or widowed was another predictor for being overweight in women. This is consistent with other studies that have mentioned marriage as a predictor for being obese $[1,6]$ and overweight among women [17]. Prior studies have shown that entering marriage is associated with gaining weight [34]. The reason could be relaxing about being in shape after marriage [26]. Consistent with previous findings, higher calorie intake was another predictor for being overweight. In fact, in the face of high-caloric foods, more self-reported impulsivity is reported, which increases susceptibility to speeded detection of such foods in obese individuals [35]. Similar to previous studies [17, 28 ], the current research found that women with a history of cigarette smoking were less likely to be overweight. One reason for this association might be the role of smoking in suppressing appetite [28].

Among men, low SES, history of cigarette smoking and moderate physical activity were associated with being overweight. Men with lower SES were more likely to be overweight $[13,14]$, which was consistent with the findings in men. However, findings about the associations between SES and BMI are still controversial [9, $13,14]$, which could be the result of variations in the study population's age group, nutritional habits, or level of daily activity. Among lifestyle variables, history of cigarette smoking and physical activity were significant predictors of being overweight among men. The current study showed that male smokers were more likely to be overweight. A probable reason could be having been a smoker in previous years and not currently a smoker. In line with this logic, Dare et al. (2015) confirmed that former smokers were more likely to be obese compared with current and never smokers [36]. Among men, only moderate physical activity was in significant association with being overweight. Therefore, men with moderate physical activity were at higher risk of being overweight. However, a moderate level of physical activity cannot be as effective as intense activity on an individual's BMI. Moreover, given that they have been physically active, they cared less about calorie intake, which resulted in an abnormal BMI. In addition, considering the age of the studied sample, this might be due to the prevalence of diseases such as hypothyroidism or diabetes mellitus [23, 24] or the use of certain drugs and their metabolic side effects which can result in an abnormal BMI [25].

\section{Limitation and strength}

One of the main limitations of this study was a lack of information regarding the nutritional habits of the participants, although it could be accompanied with a remarkable recall bias. Another limitation was having no information about the participants' medical and medication history, because some diseases and/or medications have proven associations with increased weight. Furthermore, we studied determinant factors of being overweight but not obesity. However, this study is unique in that the census method was used and 10,663 individuals aged between 40 and 70 years were recruited during 2015 and 2016. It is worth noting that physical activity was measured through MET, which is one of the most reliable measures for level of physical activity.

\section{Conclusions}

The current study revealed differences in sociodemographic and lifestyle factors of being overweight according to gender. As being overweight was more prevalent among women, the priority of policies to control this issue should be focused on women. For further actions to control future obesity, considering related factors for each gender separately should not be neglected.

\section{Abbreviations \\ BMI: High Body Mass Index; WHO: World Health Organization; SES: Socio- economic status; PERSIAN: Prospective Epidemiological Research Studies in Iran; MET: Metabolic equivalent rate; SPSS: Statistical Package for Social Sciences; OR: Odds ratio; Cl: Confidence interval}

\section{Acknowledgments}

This article was extracted from Dr. Seyed Alireza Dastgheib's thesis in partial fulfillment of the requirement for the degree of doctor of medicine (proposal No. 98-01-01-19937). The authors would like to express their gratitude to the Vice Chancellor for Research of Shiraz University of Medical Sciences for financially supporting the project. The authors would also like to acknowledge the Fars Birth Cohort Clinic staff and mothers who participated in the study.

\section{Authors' contributions}

Author Contributions: Study concept and design: N. M., and A.R.; Acquisition of data: S.A.D., S.R.; Analysis and interpretation of data: N. M., S.A.D., A. R., S. R. and K.B.L.; Drafting of the manuscript: N. M., S.A.D. and A. R.; Critical revision of the manuscript for important intellectual content: N. M., A. R. S. R. and K. B. L.; Statistical analysis: N.M. and S. R.; Administrative, technical, and material support: S.A.D., N.M., and A. R.; Study supervision: N. M, K.B.L., S. R. and A.R. All authors have read and approved the final manuscript.

\section{Funding}

This study was supported by grant no. 98-01-01-19937 from the Vice Chancellor for Research, Shiraz University of Medical Sciences, Shiraz, Iran.

\section{Availability of data and materials}

The datasets used and analyzed during the current study are available by sending an email to the owner of data (Abbas Rezaianzadeh; rezaiana@gmail.com).

\section{Declarations}

Ethics approval and consent to participate

The study was approved by the Ethics committee of Shiraz University of Medical Sciences (IR.sums.med.rec.1398.340). The written informed consent was obtained from all participants [19]. 


\section{Consent for publication}

Not Applicable.

\section{Competing interests}

The authors report no conflict of interest.

\section{Author details}

'Student Research Committee, Shiraz University of Medical Sciences, Shiraz, Iran. ${ }^{2}$ Colorectal Research Center, Shiraz University of Medical Sciences, Shiraz, Iran. ${ }^{3}$ Health Policy Research Center, Institute of Health, Shiraz University of Medical Sciences, Shiraz, Iran.

Received: 18 August 2020 Accepted: 8 April 2021

Published online: 17 April 2021

\section{References}

1. Moghimi-Dehkordi B, Safaee A, Vahedi M, Pourhoseingholi A, Pourhoseingholi M, Ashtari S, et al. Overweight and obesity and related factors in urban Iranian population aged between 20 to 84 years. Ann Med Health Sci Res. 2013;3(2):171-6. https://doi.org/10.4103/2141-9248.113656.

2. Abdelaal M, le Roux CW, Docherty NG. Morbidity and mortality associated with obesity. Ann Transl Med. 2017;5(7):161.

3. Rybnikova N, Haim A, Portnov BA. Does artificial light-at-night exposure contribute to the worldwide obesity pandemic? Int J Obes. 2016;40(5):81523. https://doi.org/10.1038/ijo.2015.255.

4. World Health Organization. Obesity and overweight. 2020. Retrived from: https://www.who.int/news-room/fact-sheets/detail/obesity-and-overweight.

5. Jafari-Adli S, Jouyandeh Z, Qorbani M, Soroush A, Larijani B, Hasani-Ranjbar S. Prevalence of obesity and overweight in adults and children in Iran; a systematic review. J Diabetes Metab Disord. 2014;13(1):121. https://doi.org/1 0.1186/s40200-014-0121-2

6. Tabrizi JS, Sadeghi-Bazargani H, Farahbakhsh M, Nikniaz L, Nikniaz Z. Prevalence and associated factors of overweight or obesity and abdominal obesity in Iranian population: a population-based study of northwestern Iran. Iran J Public Health. 2018:47(10):1583-92.

7. Nikooyeh B, Abdollahi Z, Salehi F, Nourisaeidlou S, Hajifaraji M, Zahedirad M, et al. Prevalence of obesity and overweight and its associated factors in urban adults from West Azerbaijan, Iran: the National Food and nutritional surveillance program (NFNSP); 2016.

8. Barzin M, Valizadeh M, Serahati S, Mahdavi M, Azizi F, Hosseinpanah F. Overweight and obesity: Findings from 20 years of the Tehran Lipid and Glucose Study. Int J Endocrin Metab. 2018;16(4 Suppl):e84778.

9. Khabazkhoob M, Emamian MH, Hashemi H, Shariati M, Fotouhi A. Prevalence of overweight and obesity in the middle-age population: priority for the health system. Iran J Public Health. 2017;46(6):827-34.

10. Newton S, Braithwaite D, Akinyemiju TF. Socio-economic status over the life course and obesity: Systematic review and meta-analysis. PLoS One. 2017; 12(5):e0177151.

11. Pouliou T, Elliott SJ. Individual and socio-environmental determinants of overweight and obesity in urban Canada. Health Place. 2010;16(2):389-98. https://doi.org/10.1016/j.healthplace.2009.11.011.

12. Sarma H, Saquib N, Hasan MM, Saquib J, Rahman AS, Khan JR, et al. Determinants of overweight or obesity among ever-married adult women in Bangladesh. BMC Obes. 2016;3(1):13. https://doi.org/10.1186/s40608-016-0093-5.

13. Asp M, Simonsson B, Larm P, Molarius A. Physical mobility, physical activity, and obesity among elderly: findings from a large population-based Swedish survey. Public Health. 2017;147:84-91. https://doi.org/10.1016/j.puhe.2017.01.032.

14. Vanhelst J, Baudelet J-B, Fardy PS, Beghin L, Mikulovic J, Ulmer Z. Prevalence of overweight, obesity, underweight and normal weight in French youth from 2009 to 2013. Public Health Nutr. 2017;20(6):959-64. https://doi.org/1 $0.1017 / S 1368980016003244$

15. Satti MN, Khalid M: Prevalence and Determinants of Overweight and Obesity Among Adults in Pakistan. Accessed 21 Jan 2019.

16. Chan YY, Lim KK, Lim KH, Teh CH, Kee CC, Cheong SM, et al. Physical activity and overweight/obesity among Malaysian adults: findings from the 2015 National Health and morbidity survey (NHMS). BMC Public Health. 2017;17(1):733. https://doi.org/10.1186/s12889-017-4772-z.

17. Gaio V, Antunes L, Namorado S, Barreto M, Gil A, Kyslaya I, et al. Prevalence of overweight and obesity in Portugal: results from the first Portuguese health examination survey (INSEF 2015). Obes Res Clin Pract. 2018;12(1):4050. https://doi.org/10.1016/j.orcp.2017.08.002.
18. Karyani AK, Matin BK, Soltani S, Rezaei S, Soofi M, Salimi Y, et al. Socioeconomic gradient in physical activity: findings from the PERSIAN cohort study. BMC Public Health. 2019;19(1):1312. https://doi.org/10.1186/s12889-019-7715-z.

19. Poustchi H, Eghtesad S, Kamangar F, Etemadi A, Keshtkar A-A, Hekmatdoost $A$, et al. Prospective epidemiological research studies in Iran (the PERSIAN cohort study): rationale, objectives, and design. Am J Epidemiol. 2018;187(4): 647-55. https://doi.org/10.1093/aje/kwx314.

20. Statistical center of Iran. Population and Housing Censuses. 2016. retrived from: https://www.amar.org.ir/english/Population-and-Housing-Censuses.

21. Centers for Disease Control and Prevention (CDC). Defining Adult Overweight and Obesity. retrived from: https://www.cdc.gov/obesity/adult/defining.html. Accessed 2 Feb 2021

22. World Health Organization. Waist circumference and waist-hip ratio: report of a WHO expert consultation, Geneva, 8-11 December 2008: World Health Organization; 2011. Retrived from: https://apps.who.int/iris/bitstream/ha ndle/10665/44583/9789241501491_eng.pdf?sequence=1\&isAllowed=y

23. Jin HY. Prevalence of subclinical hypothyroidism in obese children or adolescents and association between thyroid hormone and the components of metabolic syndrome. J Paediatr Child Health. 2018;54(9): 975-80. https://doi.org/10.1111/jpc.13926.

24. Abdullah A, Peeters A, de Courten M, Stoelwinder J. The magnitude of association between overweight and obesity and the risk of diabetes: a meta-analysis of prospective cohort studies. Diabetes Res Clin Pract. 2010; 89(3):309-19. https://doi.org/10.1016/j.diabres.2010.04.012.

25. Reynolds GP, Kirk SL. Metabolic side effects of antipsychotic drug treatment-pharmacological mechanisms. Pharmacol Ther. 2010;125(1):16979. https://doi.org/10.1016/j.pharmthera.2009.10.010.

26. Bove CF, Sobal J. Body weight relationships in early marriage. Weight relevance, weight comparisons, and weight talk. Appetite. 2011;57(3):72942. https://doi.org/10.1016/j.appet.2011.08.007.

27. Ogden CL, Fakhouri TH, Carroll MD, Hales CM, Fryar CD, Li X, et al. Prevalence of obesity among adults, by household income and education-United States, 2011-2014. MMWR Morb Mortal Wkly Rep. 2017; 66(50):1369-73. https://doi.org/10.15585/mmwr.mm6650a1.

28. Jacobs M. Adolescent smoking: the relationship between cigarette consumption and BMI. Addict Behav Rep. 2019;9:100153. https:/doi.org/10.1016/j.abrep.2018.1 00153.

29. Bradbury KE, Guo W, Cairns BJ, Armstrong ME, Key TJ. Association between physical activity and body fat percentage, with adjustment for BMl: a large cross-sectional analysis of UK biobank. BMJ Open. 2017;7(3):e011843. https:// doi.org/10.1136/bmjopen-2016-011843.

30. Gouda J, Prusty RK. Overweight and obesity among women by economic stratum in urban India. J Health Popul Nutr. 2014;32(1):79.

31. Zarei $\mathrm{N}$, Ahmadi A. Nutrition transition: an intergenerational comparison of dietary habits among women of shiraz. Iran J Public Health. 2015;44(2):269-75.

32. Noh J-W, Kim J, Park J, Oh I-H, Kwon YD. Age and gender differential relationship between employment status and body mass index among middle-aged and elderly adults: a cross-sectional study. BMJ Open. 2016; 6(11):e012117. https://doi.org/10.1136/bmjopen-2016-012117.

33. Dave DM, Kelly IR. How does the business cycle affect eating habits? Soc Sci Med. 2012;74(2):254-62. https://doi.org/10.1016/j.socscimed.2011.10.005.

34. Klos LA, Sobal J. Marital status and body weight, weight perception, and weight management among US adults. Eat Behav. 2013;14(4):500-7. https:// doi.org/10.1016/j.eatbeh.2013.07.008.

35. Bongers $\mathrm{P}$, van de Giessen E, Roefs A, Nederkoorn C, Booij J, van den Brink $W$, et al. Being impulsive and obese increases susceptibility to speeded detection of high-calorie foods. Health Psychol. 2015;34(6):677-85. https:// doi.org/10.1037/hea0000167.

36. Dare S, Mackay DF, Pell JP. Relationship between smoking and obesity: a crosssectional study of 499,504 middle-aged adults in the UK general population. PLoS One. 2015;10(4):e0123579. https://doi.org/10.1371/journal.pone.0123579.

\section{Publisher's Note}

Springer Nature remains neutral with regard to jurisdictional claims in published maps and institutional affiliations. 